LA INVENCIÓN DEL PATRIMONIO NATURAL EN ESPAÑA. POLÍTICA, ACADEMIA, ACTIVISMO Y COMUNICACIÓN /

THE INVENTION OF NATURAL HERITAGE IN SPAIN. POLITICS, ACADEMY, ACTIVISM AND COMMUNICATION

\section{LA PERCEPCIÓN DEL MEDIO AMBIENTE EN EL POST- FRANQUISMO. LA EMERGENCIA DE LOS PARQUES NATURALES EN CATALUÑA (1975-1990s)}

\author{
Judit Gil-Farrero \\ Universitat Autònoma de Barcelona \\ juditgil@gmail.com
}

\section{THE PERCEPTION OF THE ENVIRONMENT AFTER FRANCOISM. THE EMERGENCE OF NATURAL PARKS IN CATALONIA (1975-1990s)}

Cómo citar este artículo/Citation: Gil-Farrero, J. (2016). La percepción del medio ambiente en el post-franquismo. La emergencia de los Parques Naturales en Cataluña (19751990s). Arbor, 192 (781): a348. doi: http://dx.doi.org/10.3989/ arbor.2016.781n5006

Recibido: 25 febrero 2015. Aceptado: 09 octubre 2015.
RESUMEN: En los años 70 en Cataluña comienza un cambio en la percepción que la población tiene sobre la naturaleza, que pasa de ser una fuente de materia prima o superficie edificable a ser vista de un modo más amplio como patrimonio natural a conservar. A mediados de esa década comienzan a aparecer movimientos populares locales y regionales para la conservación de la naturaleza cuyos principales objetivos son la divulgación de los valores naturales de determinadas zonas y la protección de las mismas. En esta tarea reciben el apoyo de la comunidad científica, nacional e internacional, y la cobertura y complicidad de los medios de comunicación, que permiten que los conflictos se den a conocer entre el gran público. Este cambio de percepción también queda plasmado más adelante en leyes que definen y desarrollan nuevos modelos de protección de la naturaleza.

PALABRAS CLAVE: percepción de la naturaleza; cambio; movimientos populares; conservación de la naturaleza; espacios protegidos.
Copyright: (C 2016 CSIC. Este es un artículo de acceso abierto distribuido bajo los términos de la licencia Creative Commons Attribution (CC BY) España 3.0.
ABSTRACT: In the 1970s in Catalonia, people's perception of nature changed from being regarded as a source of raw materials or buildable surfaces to becoming natural heritage requiring conservation. In the middle of the decade, regional and local movements for the conservation of nature began to appear. The main objective of these was to disseminate the natural values of certain areas and their need for protection. These movements received the support of the national and international scientific communities, and the coverage and complicity of the media, permitting conflicts to reach the general public. This change in perception was also reflected later in laws that defined and developped new nature protection models.

KEYWORDS: perception of nature; change; popular movements; nature conservation; protected areas. 


\section{LA CONSTRUCCIÓN SOCIAL DE LA NATURALEZA}

"Solo después de que se haya talado el último árbol, solo después de que se haya envenenado el último río, solo después de que se haya pescado el último pez, solo entonces se dará cuenta el hombre blanco de que el dinero no se puede comer."

Esta famosa profecía de los indios Cree (Potocnik, 2010) se considera una evidencia de la gran diferencia entre cómo percibían la naturaleza los indios americanos y cómo la percibían los colonos llegados de Europa. El choque cultural entre las visiones sobre la naturaleza de indios americanos y colonos europeos, ampliamente estudiado y analizado, es un ejemplo ilustrativo de que la naturaleza no es solo algo inmóvil y estático que está ahí fuera, separado de nosotros los humanos, sino un conjunto de ideas, significados, pensamientos y sentimientos creado por las personas (Worster, 1988). La naturaleza sería un espejo en el que proyectaríamos nuestras propias ideas y valores, pero también una realidad material que pondría límites (nunca completamente claros pero no por ser inciertos menos definitivos) a las posibilidades de la ingenuidad y de la narración humanas (Cronon, 1996). El concepto de naturaleza es, pues, una construcción social, y por lo tanto ha variado a lo largo del tiempo y en las distintas regiones del planeta. Es importante tener en cuenta que no solo las distintas sociedades o culturas desarrollan visiones de la naturaleza, a su vez, los individuos que las forman la perciben de maneras distintas (Worster, 1988). Pero más allá de estas diferencias, los individuos de una misma cultura y sociedad comparten, a grandes rasgos, una visión general común de la naturaleza. Las diferentes sociedades han gestionado la naturaleza en función de la percepción que de ella tenían, y esta gestión, por su parte, ha modificado el entorno, inmediato al principio, y más alejado con el tiempo, y ha conformado un paisaje, que es básicamente la parte de la naturaleza que podemos apreciar con nuestros sentidos.

Una muestra de ello es la Antigüedad clásica. Tanto la cultura griega como la romana compartieron una misma determinación de dominar el medio ambiente a través de la razón (Worster, 1988). Y esa voluntad se plasmó en una sobreexplotación de los recursos y un deterioro ambiental tales que fueron descritos por autores coetáneos. En el caso de Grecia, Hesíodo nos habla de sobrepastoreo, erosión y falta de nutrientes causadas por cultivo intensivo, sobrexplotación forestal, caza excesiva y sobrepesca, así como agotamiento de minerales por extracción de mármol y minería (Merchant, 2004). El caso del Imperio Romano fue similar, pero a mayor escala: deforestación, sobrepastoreo, erosión y pérdida de suelo fértil, salinización del suelo, extinción de especies vegetales y animales, sobre todo depredadores, nuevas grandes extensiones cultivadas, contaminación debida a la industria minera y metalúrgica y problemas de salud derivados de la mala gestión de residuos líquidos y sólidos (Hughes, 2007).

Más adelante, el Renacimiento y la tan discutida "Revolución Científica" trajeron consigo un cambio sustancial en la relación humanidad-naturaleza, tan importante que hay quien se ha referido a él como "la muerte de la naturaleza". Con la filosofía mecanicista, o materialismo científico, la naturaleza dejó de ser concebida como un organismo viviente y pasó a ser una máquina compuesta de partículas inertes y pasivas, cuyas partes eran reemplazables por otras nuevas. La ciencia también cambió y se transformó en una metodología no solo para conocer, sino también para controlar y explotar la naturaleza para el beneficio del hombre, que ya no formaba parte de aquélla (Merchant, 1989; Barca, 2008). Por su parte, el componente económico del materialismo, surgido en el siglo XVIII, que defendía la idea de que la meta más importante era conseguir la mayor riqueza personal, ha tenido un profundo impacto en la naturaleza con su asunción de que las cosas únicamente tienen valor si sirven para algún uso humano directo o pueden ser cambiadas por algo que también tenga valor. Es esta concepción la que mayor peso ha tenido en la percepción de la naturaleza desde entonces, más que el mito judeocristiano de derecho al dominio de la tierra, pues de hecho, la religión ha actuado como contrapeso, enseñando que hay metas más nobles que el consumo (Worster, 1993).

Pronto se notaron los efectos de la concepción mecanicista y materialista de la naturaleza. La explotación de los recursos naturales llevada a cabo en Europa desde finales del Renacimiento hasta la llustración produjo un deterioro en la calidad ambiental que fue plasmada por los poetas del siglo XVIII, sobre todo los románticos, pero también en otras manifestaciones artísticas como la pintura de finales de siglo. Durante la segunda mitad del siglo XVII y en el siglo XVIII comenzó a cambiar la percepción que se tenía del mundo como una creación divina al servicio de la humanidad, que lo tenía que dominar, y se empezó a ver como un universo diseñado por un Dios sabio que había designado a los humanos para que lo cuidaran y así glorificaran a Dios y mejora- 
ran su condición humana (Brimblecombe, 1987). Entre otros aspectos, el discurso del Romanticismo del siglo XIX lamentaba la degradación de una naturaleza original, prístina, creada por Dios, y admiraba de manera especial las partes de la naturaleza que el ser humano no había llegado a modificar (Merchant, 2004). El poso del discurso romántico permaneció a lo largo del siglo XIX y durante el siglo XX, cuando la naturaleza se convirtió en una fuente de legitimidad e identidad de naciones como la estadounidense (Casado, 2010a), asociándose lo silvestre con el carácter nacional (Merchant, 2007); la italiana, con las montañas y sus habitantes como un motivo principal en los discursos nacionalistas (Armiero, 2011); la alemana, estrechamente relacionada con el paisaje y su transformación (Blackbourn, 2007; Armiero y Von Hardenberg, 2014) o la española, donde a finales del siglo XIX se produjo "el verdadero descubrimiento de la naturaleza" española, que se convirtió en la base para la regeneración económica y moral del país (Casado, 2010a).

En este artículo avanzamos hasta el último cuarto del siglo XX para analizar el cambio que se produjo en la percepción de la naturaleza en Cataluña, donde los años 70 presenciaron lo que se ha llamado nacimiento de la conciencia ambiental. Durante esa década y la siguiente se pasó de entender la degradación y la contaminación del entorno como algo normal, un efecto colateral del progreso, a verlas como una situación insostenible e intolerable. La naturaleza se revalorizó y comenzó a ser considerada "patrimonio natural" que había que conservar. Este cambio de percepción se vio reflejado en el tratamiento de una serie de problemas de degradación ambiental, pero en este trabajo nos vamos a centrar concretamente en la protección de espacios naturales en Cataluña, donde a principios de la década de los 80 se declaraban Parque Natural la Zona Volcànica de la Garrotxa (1982) y los Aiguamolls de l'Empordà (1983), tras años de campaña reivindicativa para su protección, y el Delta de l'Ebre (1983), tras una movilización popular en contra de unas desecaciones que se habían llevado a cabo en el conjunto lacustre del Canal Vell. Además de estas tres zonas protegidas, durante los años 80 , la Generalitat declaró otros cuatro Parques Naturales, tres Parajes Naturales de Interés Nacional y unas Reservas Naturales. En la década de los 90 se protegió otro Parque Natural más. En este cambio de percepción sobre la naturaleza, que debe enmarcarse en un contexto internacional, jugaron un papel importante determinados actores (científicos, medios de comunicación, políticos, población local), que utilizaron distintas estrategias para conseguir sus objetivos, tal como veremos más adelante.

\section{LA VISIÓN OCCIDENTAL DE LA NATURALEZA DURANTE LA GUERRA FRÍA}

Las décadas de los 60 y 70 vieron lo que se ha dado en llamar "despertar ecologista internacional". Se suele situar el inicio de este proceso en 1962, año de publicación de Silent Spring, libro en el cual su autora, la zoóloga acuática estadounidense Rachel Carson, denunciaba los efectos perniciosos que el DDT y otros pesticidas tenían no solo sobre los insectos sino sobre el medio ambiente (Carson, 2001) y que se convertiría en una especie de mito fundacional de una nueva sensibilidad ambiental. La década siguiente asistiría a la publicación de otras obras cuyo tema principal era el estado del medio ambiente, como por ejemplo Science and Survival (1967), de Barry Commoner; The environmental revolution (1970), de Max Nicholson; The entropy law and the economic process (1971), de Nicolae Georgescu-Roegen; el manifiesto de la revista británica The Ecologist "Blueprint of Survival" (1972) o el libro de Ernst Friedrich Schumacher Small is Beautiful (1973) (Camarasa, 2007).

Los años 60 fueron una época de aparición de movimientos sociales a nivel mundial, entre los que cabe destacar el ecologismo en sus distintas vertientes, cuyo éxito se podría asociar al crecimiento económico de las potencias industriales, que habría propiciado que la mayoría de su población pudiera permitirse preocuparse por otros asuntos más allá del dinero, como serían el aumento de la contaminación y de los productos químicos peligrosos (McNeill, 2003). Algunos de estos movimientos se pueden enmarcar dentro del llamado ecologismo de los pobres, ecologismo popular o movimientos de la justicia ambiental, con una larga lista de ejemplos en distintas partes del mundo, si bien los propios actores lo han percibido comúnmente como un conflicto social y en muchos casos no se consideran a ellos mismos ecologistas (Martínez Alier, 2006). Otros se pueden sumar a la más o menos larga tradición de los movimientos proteccionistas. A finales del siglo XIX en los EUA aparecieron los movimientos de conservación y preservación, que compartían el objetivo de recuperar la tierra pero diferían en su enfoque: mientras los conservacionistas, liderados por Gifford Pinchot, pretendían convertir la explotación ciega de los recursos naturales en otra racional, los preservacionistas, con John Muir a la cabeza, pedían preservar la naturaleza prístina, entendida como aquello silvestre, mediante parques (Merchant, 2004; Martínez Alier, 2006). Ya en el siglo XX, estos movimientos se extendieron a otros países, sobre todo en Europa, donde, por ejemplo, a mediados del siglo XX, 
numerosos países tenían un cierto número de zonas protegidas bajo la figura de Parque Nacional y otras.

La temática ambiental llegaba al plano político en la década de los 70. Tras la Segunda Guerra Mundial habían surgido numerosas instituciones internacionales, algunas de ellas preocupadas por el medio ambiente, como la Unión Internacional para la Conservación de la Naturaleza (UICN, 1948), y otras que regulaban la intervención en él, como la Organización Mundial de la Salud (OMS, 1948), la Organización para la Agricultura y la Alimentación (FAO, 1945) y la Organización de las Naciones Unidas para la Educación, la Ciencia y la Cultura (UNESCO, 1945), pero no hubo ninguna medida o corriente política coordinada que tuviera como objetivo el medio ambiente en sí hasta la década de los 70 (McNeill, 2003). El Consejo de Europa proclamó en Estrasburgo el 1970 "Año Europeo de la Conservación de la Naturaleza". El Club de Roma encargó en 1972 al Massachussets Institute of Technology un informe que se tituló The Limits to Growth, cuya conclusión fue que si el modelo de crecimiento de la sociedad moderna se mantenía como en aquel momento, la esperanza de vida de la sociedad en el planeta era de unos 100 años. El mismo año se celebró en Estocolmo la Primera Conferencia de Naciones Unidas sobre Medio Ambiente Humano, en la que los delegados de 113 Estados acordaron un plan de acción en la cual precisaban las aportaciones consideradas necesarias para afrontar la crisis ambiental, con la educación como uno de los caminos indispensables. Siguiendo una recomendación de esta conferencia se creó el Programa de las Naciones Unidas para el Medio Ambiente (PNUMA). En 1977, la UNESCO organizó, en cooperación con el PNUMA, la Conferencia Intergubernamental sobre Educación Ambiental en Tbilisi. Ya en 1980, el PNUMA y el World Wildlife Fund (WWF, fundado en 1961) encargaron la preparación de la Estrategia Mundial para la Conservación a la UICN (Boada y Saurí, 2002).

En la esfera científica, la ecología como ciencia también tomaba impulso en esta época. Entre los años 1964 y 1974 se llevó a cabo el International Biological Program (IBP), que perseguía la comprensión de los sistemas terrestres a través de estudios ecosistémicos comparativos en un rango de biomas en todo el mundo, si bien con ello se pretendía mejorar la gestión y el uso de las áreas protegidas para satisfacer las necesidades de la sociedad (Anderson et al., 2008). Nacida a finales del siglo XIX, la ecología había experimentado una interesante evolución durante el siglo XX. Hasta los años 30, la ecología básicamente estudiaba el equilibrio, la armonía y el orden de la naturaleza. La llamada "ecología dinámica" estudiaba el cambio y la evolución en el paisaje, y desarrolló el concepto de sucesión ecológica en un terreno perturbado, donde primero aparecen especies pioneras que preparan el terreno para otras especies, hasta llegar al clímax. En la década siguiente, en cambio, se acercó a la física con sus conceptos de flujos de energía y de nutrientes, niveles tróficos y ecosistemas. En las décadas posteriores los protagonistas fueron los ecosistemas en que estaba organizada la naturaleza, cuya estrategia de desarrollo iba hacia un mundo de mutualismo y cooperación entre los organismos que vivían en una cierta área hasta llegar a la madurez del ecosistema (homeostasis). En la década de los 70 se llegó a la ecología del caos: se empezaron a estudiar las perturbaciones, sobre todo las de origen no humano, y se afirmó que no había plan ni armonía aparente en los sucesos de la naturaleza (Worster, 1993). La idea de la naturaleza como una comunidad estable, holística y homeostática que puede mantener su equilibrio si los humanos no la perturban está en la base de muchas de las ideas populares acerca del medio ambiente (Cronon, 1996).

La ecología no fue la única ciencia que floreció en esta época. El escenario de la Guerra Fría propició un extraordinario desarrollo de las geociencias que contribuyó a un mayor conocimiento del planeta y a su visión como un todo cuyas partes están interconectadas. Prosperó la prospección de minerales como el uranio, esencial en el armamento nuclear, pero también en la generación de energía, de fosfatos, básicos para aportar fertilidad a los suelos agrícolas y de combustibles fósiles (gas y petróleo). La meteorología y la sismología se convirtieron en ciencias clave que dejaban constancia de las pruebas nucleares llevadas a cabo en el bloque contrario, y el desarrollo de la oceanografía proporcionó la información necesaria para mejorar la capacidad de detección de submarinos a partir del sónar. La carrera espacial, por su parte, proporcionó a la población mundial las primeras imágenes de la Tierra desde el exterior, contribuyendo así de un modo muy visual a su percepción global (Turchetti et al., 2012; Camprubí, 2014).

\section{EL ESTADO DEL MEDIO AMBIENTE EN ESPAÑA EN LOS AÑOS 70}

La descripción de la degradación ambiental en la España de los 70 es abrumadora: reservas de materias primas en rápida reducción, grandes extensiones convertidas en yermos improductivos debido a la pér- 
dida de su cubierta vegetal y la consecuente erosión por lluvia y viento; aguas marinas y continentales altamente contaminadas y alteradas; contaminación atmosférica, que supone un peligro para la salud de los seres vivos; desaparición acelerada de especies vegetales y animales como consecuencia de la destrucción de sus ecosistemas o de la acción humana directa (como la sobrepesca en aguas canarias (Díez de la Paz, 1993)), aparición de suburbios insalubres en las grandes ciudades, vertederos por doquier (figura 1) y en general una planificación territorial inexistente y un urbanismo totalmente incontrolado (Bolòs, 1973), en parte debido al fenómeno de las segundas residencias, así como a los Planes de Desarrollo, que priorizaban los ingresos derivados del turismo por delante de cualquier consideración ambiental. Además del turismo, el desarrollismo también afectó a otros ámbitos donde generó conflictos ambientales que provocaron protestas locales relacionadas con la contaminación industrial, los grandes trabajos hidráulicos, la construcción de centrales nucleares, las condiciones de saneamiento o sanidad ambiental, la calidad de vida, etc. (Corral Broto, 2011).

En contraste con esta situación, determinadas zonas del país se hallaban protegidas por distintas regulaciones. Por una parte, en el marco de la desamortización que tuvo lugar en el siglo anterior, se llevó a cabo el primer Catálogo de Montes de Utilidad Pública, que preservó los bosques protectores situados en las cabeceras de las cuencas hidrográficas, dada su regulación del régimen hidrológico y su protección frente a riadas e inundaciones, aludes, caída de rocas y erosión (Casado, 2010b). Por otra parte, desde

Figura 1. Vertedero del volcán del Croscat (Zona Volcànica de la Garrotxa) [c. 1980].

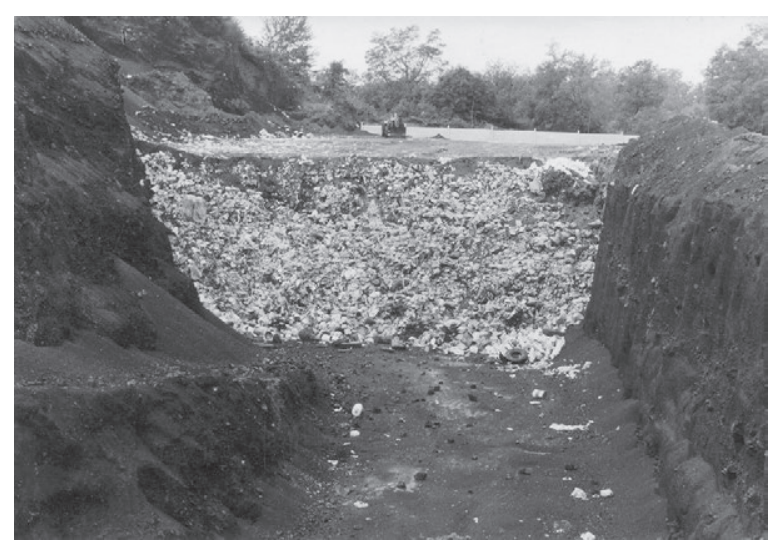

Fuente: Arxiu Comarcal de la Garrotxa. Servei d'Imatges. Fons l'Olotí. Autor desconocido. principios de siglo se habían ido protegiendo ciertos espacios naturales. En 1916 se había aprobado la Ley de Parques Nacionales con la intención de crear santuarios de la naturaleza donde se pudiera volver a la unión entre naturaleza y humanidad al estilo de los que habían creado en los EUA desde 1872. Dos años después se creaban el Parque Nacional de la Montaña de Covadonga y el Parque Nacional del Valle de Ordesa. En la línea de los primeros parques nacionales norteamericanos, se pretendían proteger aquellas zonas supuestamente no (o poco) alteradas por la humanidad. Se consideraba que había zonas, pues, que merecían ser protegidas por razones estéticas, más que por su valor ecológico, por la necesidad de ofrecer un espacio puro y prístino a una población urbana cada vez más alejada de la naturaleza (Casado, 2009). El decreto que desarrolló la Ley de Parques Nacionales clasificó las figuras de protección, añadiendo a la de Parque Nacional las de Lugar Nacional, Particularidad o Curiosidad Excepcional y Árbol Notable (Mulero Mendigorri, 2002). Bajo la Ley de Parques Nacionales, en la década de los 50 se declararon otros tres Parques Nacionales: el del Teide y el de Caldera de Taburiente (1954) y el de Aigüestortes i Estany de Sant Maurici (1955). En 1957, la Ley de Montes derogó la ley anterior y mientras fue vigente se declararon otros tres Parques Nacionales: el de Doñana (1969), el de las Tablas de Daimiel (1973) y el de Timanfaya (1974).

En 1971 se creaba el Instituto Nacional para la Conservación de la Naturaleza (ICONA), integrado en un ministerio compuesto por ingenieros agrónomos, forestales o de montes, con finalidad protectora pero dimensión forestal y productivista, como estrategia de legitimación de España en la cumbre de Naciones Unidas de 1972. Se crearon también comisiones subordinadas a la Comisaría de los Planes de Desarrollo, como la Comisión Interministerial de protección del Medio Ambiente, que asistía a otra creada a la vez, la Comisión Delegada del Gobierno para el Medio Ambiente, que pretendía retóricamente "luchar contra la contaminación atmosférica y de las aguas, la defensa del paisaje y de los recursos naturales, la conservación del patrimonio histórico-artístico y, en general, la necesidad de salvaguardar la calidad del medio ambiente" (Corral Broto, 2011). Desde su creación, el ICONA fue introduciendo modificaciones provisionales a la Ley de Montes hasta la presentación de un proyecto de ley que se convertiría en la Ley de Espacios Naturales Protegidos (1975), que, entre otros cambios, reclasificó los Espacios Naturales Protegidos hasta la fecha en cuatro categorías: Reserva Integral, Parque Nacional, Paraje Natural de Interés Nacional y Parque Natu- 
ral. Esta nueva ley comportó un cambio significativo en la concepción y la gestión de la naturaleza, dado que permitía proteger distintos espacios, cada uno con la figura que mejor le convenía, y tenía en cuenta sus valores naturales y no solo los paisajísticos (Mulero Mendigorri, 2002). Así pues, en esta última ley aparece por primera vez la figura de Parque Natural, que tuvo una amplia aceptación, como se desprende del hecho que en 1989 (cuando se promulgó la nueva Ley de conservación de los espacios naturales protegidos y de la flora y la fauna silvestres), algo más de 500.000 hectáreas de superficie se hallaban protegidas bajo esta figura de protección. Su característica principal era la voluntad de permitir y compatibilizar la conservación del medio natural, el uso público de la naturaleza y los aprovechamientos ordenados de los recursos. Este último eje era la principal diferencia entre los Parques Nacionales y los Naturales (Corraliza Rodríguez, García Navarro y Gutiérrez del Olmo, 2002).

\section{LA PROTECCIÓN DE ESPACIOS NATURALES EN CATALUÑA}

El año 1972 se produjo lo que se considera la primera reivindicación de cariz ambiental en Cataluña: el futuro emplazamiento en el Garraf de un vertedero controlado para los residuos del área metropolitana de Barcelona movilizó a 1.200 personas en Gavà. Hasta aquel momento, los residuos urbanos habían ido rellenando las canteras de la montaña de Montjuïc, pero ya a lo largo de aquel año, el Ayuntamiento de Barcelona había empezado a llevar deshechos a las áreas excavadas para la extracción de áridos en el delta del río Llobregat, situación que generó rechazo por parte de la población local por los malos olores y la contaminación de las aguas subterráneas. Cuando se hizo público el proyecto del vertedero en la Vall d'en Joan, espeleólogos de diversas entidades excursionistas alertaron sobre el proyecto y sobre la poca idoneidad de su emplazamiento, por el hecho de ser el Garraf un macizo cárstico, lleno de simas y cuevas, y fueron apoyados por la comunidad científica. Pero a pesar de la oposición popular y de los espeleólogos, dado el riesgo de contaminación de los acuíferos y de propagación del metano, producido por la fermentación de la materia orgánica, el proyecto del vertedero se llevó a cabo, y siguió en funcionamiento hasta el año 2006.

El apoyo a los espeleólogos y la población local en el caso del vertedero del Garraf fue uno de los primeros ejemplos del importante papel que la comunidad científica jugó en la denuncia del mal estado del medio natural en Cataluña. En 1973, el Dr. Oriol de Bolòs leyó un discurso en la Delegación de Barcelona del CSIC titulado La conservación de la naturaleza y sus fundamentos, en cuya primera parte describe el lamentable estado de la naturaleza en Cataluña y los abusos que sufría. A continuación reclamó la protección del patrimonio natural, dadas la necesidad de economizar las limitadas reservas materiales disponibles, la conveniencia de evitar daños que pudieran resultar del uso inadecuado de los bienes naturales, la necesidad de espacio libre y de vegetación para atender a las exigencias humanas de higiene física y psíquica y la defensa de los valores científicos y estéticos. Tras esta exposición de motivos, pidió que fueran científicos y técnicos, con conocimientos sobre el tema, visión global de la situación y buen sentido, quienes dirigieran el aprovechamiento de los recursos naturales, y que, de manera urgente, se planificara este aprovechamiento para acercarse a un nivel óptimo y así evitar la destrucción de las reservas. Esta ordenación debería fijar los espacios correspondientes a cuatro tipos fundamentales de usos del suelo y del paisaje: urbanización, cultivo agrícola, aprovechamiento silvo-pastoral y conservación del estado natural intacto. Fue una de las primeras voces que reclamó una planificación territorial equilibrada y que no se utilizara la creación de un sistema de Parques como cortina de humo que hiciera perder de vista la destrucción general que se realizaba en el resto del territorio (Bolòs, 1973).

A principios de aquel mismo año, la Institució Catalana d'Història Natural (ICHN) impulsó la redacción colectiva de un Llibre Blanc de la Gestió de la Natura dels Països Catalans. El libro se estructuró en cuatro capítulos que trataban de las bases ecológicas para gestionar la naturaleza, de sus características y los problemas generales que sufría, distribuidos según el medio; de las especies o grupos amenazados y las zonas amenazadas o conflictivas (entre ellas, la Zona Volcànica de la Garrotxa y los Aiguamolls de l'Empordà), y de orientaciones para una gestión ecológica del país, así como de directrices generales a tener presentes y de política de zonas preservadas (Folch, 1976). Finalizada la redacción en otoño de 1975, el libro se publicó el año siguiente. El éxito fue tal que en dos años se había agotado. En 1988 se hizo una segunda edición, puesta al día y ampliada, donde constaban los nuevos espacios protegidos, así como los instrumentos jurídico-administrativos de protección y gestión (Folch, 1976). La Asociación Española para la Ordenación del Medio Ambiente (AEORMA), por su parte, a principios de 1975 publicó un dossier en cuyas conclusiones manifestaba que "la calidad científica del conjunto vol- 
cánico de Olot-Santa Pau hace que cualquier intento, no hablemos ya de destrucción, sino de deformación o de desfiguración de su rocalla y su paisaje natural, sea absolutamente inaceptable, porque constituye un daño irreparable para el bien patrimonial de la cultura del país". En el caso de los Aiguamolls de l'Empordà, el conflicto recibió el apoyo de la comunidad científica internacional en el Congreso Internacional de Zonas Húmedas que se llevó a cabo en la ciudad belga de Lieja en 1976 y al que acudieron tres miembros del Grup de Defensa dels Aiguamolls Empordanesos, del que se hablará más adelante. La UICN también tuvo un papel relevante, avalando la importancia de las marismas ante el requerimiento de la empresa urbanizadora.

Pero hubo más voces a favor de la protección de la naturaleza además de las científicas. En septiembre de 1976, la Assemblea de Catalunya hizo público el manifiesto "Salvem Catalunya per la Democràcia" en que ligaba la "lucha por el retorno de la soberanía al pueblo" con el "combate para salvar el patrimonio natural de Cataluña" y hacía "un llamamiento a la movilización popular en torno a los grandes problemas que afectan al medio ambiente en Cataluña". Aquel mismo año, el Congrés de Cultura Catalana ponía en marcha cinco campañas de movilización popular, entre ellas la "Campanya per a la Salvaguarda del Patrimoni Natural", que tenía como objetivos realizar una tarea de extensión cultural, sensibilización y concienciación de la problemática ecológica; formar teórica y metodológicamente a los grupos que trabajaban en este campo, ayudándolos a articular un planteamiento globalizado y participativo; forzar las instancias pertinentes a tomar decisiones de real eficacia en materia de buen uso de los sistemas naturales, y llevar a cabo acciones territoriales concretas de corrección de malos usos. El mentado manifiesto es una muestra de que en Cataluña también se asociaron la naturaleza y la construcción nacional, como había sucedido con anterioridad en otros lugares. El elemento nacionalista apareció en los discursos de los movimientos ecologistas que surgieron en este momento histórico, así como en los de quienes abogaban por la protección de los distintos espacios. La mayoría de estos últimos movimientos seguían el lema "Salvem...", bajo el paraguas de la "Campanya per a la Salvaguarda del Patrimoni Natural": "Salvem els Volcans", "Salvem els Aiguamolls", "Salvem el Ter"...

La campaña "Salvem els Volcans" estuvo incluida en la campaña para la protección de la Zona Volcànica de la Garrotxa, cuyo origen es anterior al inicio de la "Campanya per a la Salvaguarda del Patrimoni Na- tural". Dada su ubicación interior y su entonces mala comunicación con la ciudad de Barcelona, la comarca de la Garrotxa (provincia de Girona) había escapado al urbanismo incontrolado que afectaba al litoral catalán, pero no se libraba de otros impactos. Fue uno de ellos el detonante de la campaña de protección: las extracciones en el volcán del Croscat (el más joven y con mayor altura de la península) de greda o lapilli, materiales volcánicos expulsados durante las erupciones, muy porosos y que hacia la década de los 60 se habían empezado a utilizar como materia prima en el ramo de la construcción y en las fábricas de cemento puzolánico (figura 2). A las extracciones de greda hay que sumar el uso del Croscat como vertedero "provisional" (desde principios de 1975 hasta después de la declaración de Parque Natural) por parte del Ayuntamiento de Olot, mientras se buscaba una solución definitiva para el tratamiento de los residuos municipales (figura 1).

A finales de 1974 se había creado en Olot un grupo de expertos formado por estudiantes universitarios, profesores y catedráticos de la zona que pretendían buscar los medios necesarios para conservar la Zona Volcànica de la Garrotxa. Sus vías de actuación serían la divulgación de los valores científicos de la región, la dinamización de las movilizaciones populares y la denuncia de actividades de empresas y administraciones que atentaran contra el patrimonio natural. Al año siguiente comenzó su tarea divulgadora con la edición de una publicación-denuncia, la realización de un montaje audiovisual y la elaboración de unos itinerarios pedagógicos. A finales de año se pusieron en contacto con autoridades y entidades para pedir ayuda y finalmente crearon la Comissió Promotora per a la Protecció de la Zona Volcànica (CPPZV), cuyo objetivo era la declaración de Parque Natural para toda la zona volcánica del NE de Cataluña.

La CPPZV desarrolló buena parte de su tarea divulgativa y de denuncia en la prensa provincial y comarcal, sobre todo en los semanarios Olot-misión y La Garrotxa, convertidos en 1979 en L'Olotí y La Comarca d'Olot, respectivamente. Entre los años 1975 y 1983 se publicaron más de 300 artículos, entre aquellos escritos por miembros de la comisión (figura 3) y los redactados por las propias publicaciones que se hacían eco de cómo iba evolucionando el conflicto. La tarea divulgativa fue más allá de su presencia en los medios de comunicación. Así, colaboraron en un cursillo sobre vulcanismo organizado por el Centre Excursionista d'Olot, presentaron ponencias en jornadas, seminarios y congresos, participaron en la XII Escola d'Estiu "Rosa Sensat" de Bellaterra, en la V Escola d'Estiu de 
Figura 2. Pancartas contra la explotación minera del Croscat (Zona Volcànica de la Garrotxa) en 1977.

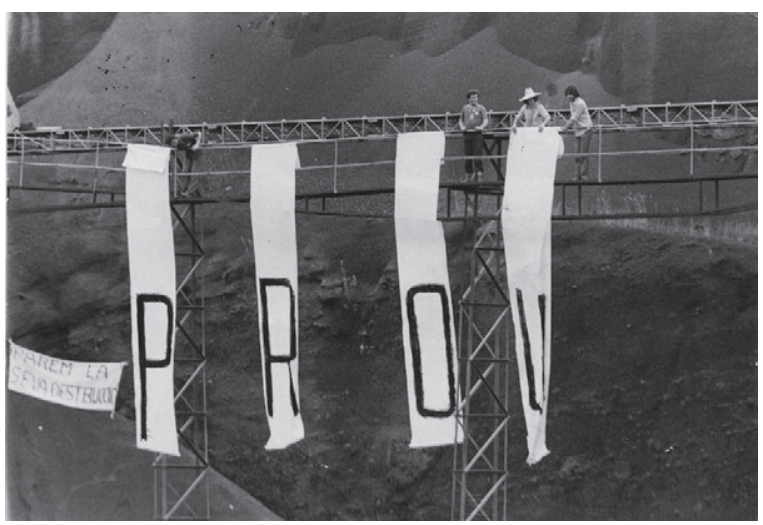

Fuente: Arxiu Comarcal de la Garrotxa. Autor: Santi Vilanova.

Figura 3. Algunos esquemas dibujados por Josep Maria Mallarach, miembro de la CPPZV, que acompañaron a artículos de su autoría.
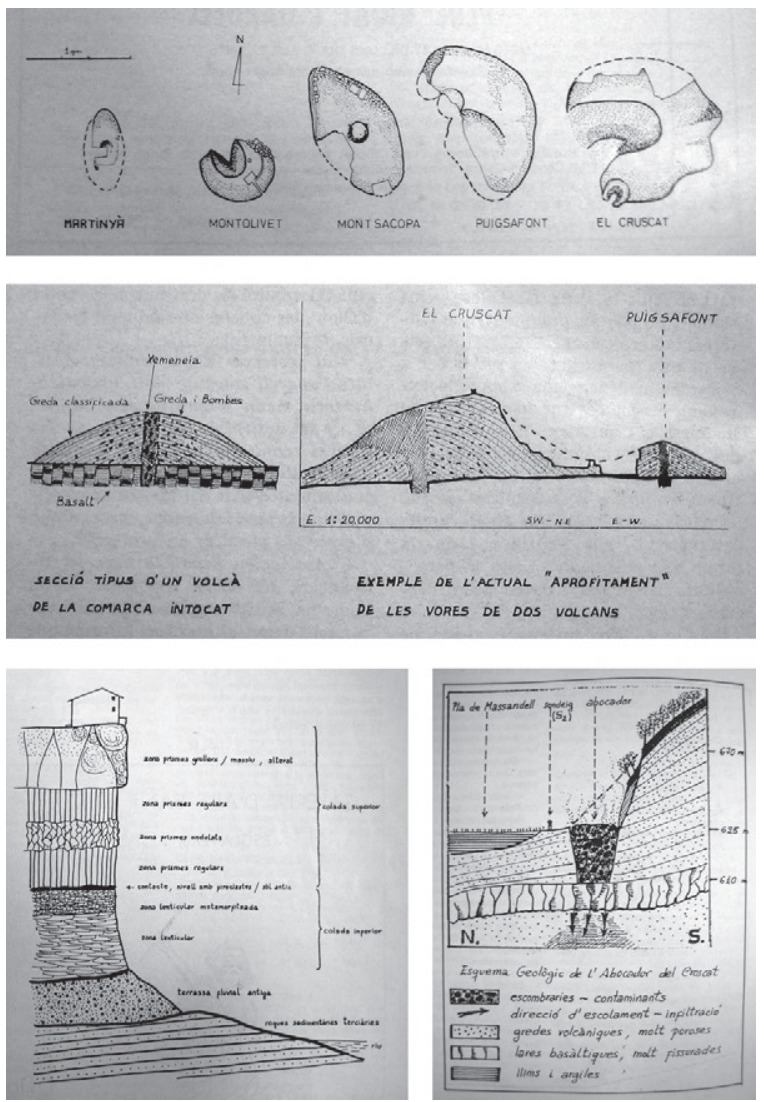

Arriba y en el centro, Olot-misión número 1.009, páginas 5 y 6. Abajo a la izquierda, Olot-misión número 1.073, página 11. Abajo a la derecha, L'olotí número 64, página 14.
Girona y en la I Escola Olotina d'Ensenyants y más adelante publicaron libros con contenido científico y pedagógico (Els volcans olotins i el seu paisatge. Iniciació a la seva coneixença segons nou itineraris pedagògics (1981), Els Volcans (1989)), con el objetivo de formar a educadores y de este modo hacer llegar a niños, niñas, adolescentes y jóvenes en edad escolar el conocimiento de la zona en la que vivían y la importancia de protegerla.

En cuanto a las movilizaciones populares, la CPPZV promovió una fiesta popular reivindicativa en la zona de extracción de greda del Croscat como culminación de la campaña "Salvem els Volcans", a la que hay que añadir los actos de clausura de la "Campanya per a la Salvaguarda del Patrimoni Natural" del Congrés de Cultura Catalana, que tuvieron lugar en Olot y los volcanes del Croscat y de Santa Margarida en octubre de 1977. Aquel mismo mes, el Ayuntamiento de Olot designó una Comisión Científica Asesora (CCA) para intentar hallar una vía de solución al conflicto de la extracción de greda. Esta comisión, formada por algunos colaboradores del Llibre Blanc (1976), algunos miembros de la CPPZV y otros científicos, elaboró un estudio donde se delimitaron unas áreas que se consideraron intocables a efectos de explotación. Tras largas negociaciones con la empresa concesionaria, ésta acordó limitar las extracciones de greda a las zonas llanas y respetar los edificios volcánicos, abandonando su actividad en el Croscat, donde volvería más adelante. Respecto a la parte de denuncia, la CPPZV impugnó el Pla General d'Urbanisme de Les Preses (1977), la Adaptació del Pla General d'Olot (1978) y el Pla Parcial Les Fonts - Mas Bernat (1978), porque en los tres casos había zonas volcánicas que quedaban desprotegidas. A finales de aquel año, la comisión se autodisolvió, considerando que había agotado sus posibilidades, si bien la campaña para la protección de la zona volcánica siguió en marcha.

Los Aiguamolls de l'Empordà, por su parte, situados en la desembocadura de los ríos Fluvià y Muga (golfo de Roses, provincia de Girona), estaban amenazados por un plan urbanístico que pretendía convertir la zona en Port Llevant, similar a la marina residencial Empuriabrava. El proyecto contemplaba una urbanización de 640 hectáreas, con una red de canales navegables y una capacidad para albergar a 65.000 personas. El plan también incluía otra urbanización, Fluvià Marina. En junio de 1976 apareció en la revista gerundense Presència el primer texto en defensa de los Aiguamolls de l'Empordà, firmado por Jordi 
Sargatal, uno de los futuros fundadores del Grup de Defensa dels Aiguamolls Empordanesos (GDAE), cuyo objetivo era impedir las urbanizaciones Port Llevant y Fluvià Marina, para lo que pusieron en marcha la campaña "Els últims aiguamolls de l'Empordà en perill". Ese mismo año, tres de los miembros del GDAE (Jordi Sargatal, Martí Boada y Francesc Giró) acudieron al congreso ornitológico en Lieja para dar a conocer las marismas a la comunidad científica internacional (Folguera, Fernández de Castro y Parrado, 2013, 3 de diciembre). El GDAE buscó cualquier resquicio legal al que aferrarse para paralizar las obras del plan urbanístico, y la única cosa que hallaron fue que la playa de los Aiguamolls, afectada por el plan, había sido declarada Paraje Pintoresco el año 1972. Así pues, presentó un recurso legal.

Entre los años 1976 y 1978, mientras esperaban respuesta al recurso legal, se hicieron oír. Sabían que en los pueblos no tenían mucho apoyo, así que desarrollaron lo que llamaban "política de la botifarra", que consistía en ir a los bares de los pueblos, sentarse con los lugareños a jugar a la botifarra, un juego de cartas típico, y como quien no quiere la cosa, sacar el tema. Organizaron manifestaciones, cursillos de divulgación sobre aves migratorias, una exposición itinerante, debates y coloquios, así como una marcha popular con medio millar de participantes, y estuvieron en cualquier acto en que se hablara de aquella zona, desde el Debat Costa Brava hasta el Congrés de Cultura Catalana. Redactaron un manifiesto que obtuvo un gran apoyo popular, y en 1977 organizaron un acto reivindicativo unitario de grupos ecologistas, con éxito de participación. La empresa urbanizadora inició las obras en distintas ocasiones. Para evitarlo, en verano de 1977 y 1978 se ocupó pacíficamente los terrenos afectados. En 1977, la decisión fue tomada por el GDAE y DEPANA (Lliga per a la Defensa del Patrimoni Natural, organización creada en 1976), y la ocupación contó con la presencia de personas no pertenecientes a ninguna de las dos entidades. En 1978, los ocupantes fueron algunos miembros del GDAE. En 1980, se creaba la Institució Altempordanesa per a I'Estudi i la Defensa de la Natura (IAEDEN), que intregraba al GDAE, y que fue quien siguió reclamando la protección de la zona.

Ambas campañas de protección aparecieron reiteradamente en los medios de comunicación. El seguimiento que de ellas hicieron permitió que se dieran a conocer no solo a nivel local o regional, sino autonómico e incluso nacional. La prensa escrita, sobre todo, pero también la televisión, jugaron un importante papel en la difusión de los conflictos, y por tanto, en la concienciación ambiental de la población. A nivel local, es interesante comentar el caso de la Garrotxa, cuyos semanarios tomaron actitudes bastante diferentes respecto al conflicto. El semanario Olot-misión / L'Olotí publicó más de 200 artículos sobre el tema, y durante un tiempo contó con uno de los miembros más activos de la CPPZV como colaborador. El semanario La Garrotxa / La Comarca d'Olot, en cambio, en el mismo intervalo de tiempo publicó poco más de 100 artículos. No es solo una cuestión de números, el tratamiento de la información tampoco es el mismo. La CPPZV encontró en el semanario Olot-misión / L'Olotí un altavoz de sus actividades. Así, sobre todo al inicio, la revista publicó un gran número de artículos muy divulgativos de los valores naturales de la región, que pretendían explicar la razón por la que aquella zona merecía ser protegida. Además de este tipo de artículos, publicó textos de denuncia de las actividades que ponían en peligro el patrimonio natural. En general, hizo un seguimiento bastante exhaustivo de todo el proceso desde una posición de apoyo a la campaña a favor de la protección. La revista La Garrotxa / La Comarca d'Olot, en cambio, no solamente no dio tanta relevancia y apoyo a la campaña, sino que incluso llegó a dar voz a la empresa minera y a algunas propuestas de urbanización de uno de los volcanes (figura 4).

Otro actor importante en estas campañas fueron las empresas minera y constructora, respectivamente, a las que les tocó jugar el papel de "malo de la película". En ambos casos, no solo sus planes y sus actuaciones estuvieron amparados por las leyes vigentes, sino que incluso contaron con el apoyo de parte de la población local, que los veía como generadores de empleo y riqueza, e incluso progreso. En ambos casos, las empresas fueron indemnizadas por la Generalitat al cesar su actividad.

En cuanto a la clase política, tanto los políticos locales como los regionales y autonómicos se pronunciaron a favor de la protección de las zonas en conflicto, actuando dentro del marco legal, pero en ocasiones concretas llevaron a cabo determinadas actuaciones que les valieron la denuncia de dejarse presionar por intereses económicos. Por poner algunos ejemplos, el Ayuntamiento de Olot designó una Comisión Científica Asesora para intentar hallar una vía de solución al conflicto de la extracción de greda. En cambio, en un momento dado se planteó la posibilidad de que el consistorio usara sus competencias y paralizara las extracciones mientras la empresa minera no solicitara al Ayuntamiento los permisos que se requerían para 
Figura 4. Imágenes de cubiertas y páginas interiores de revistas referentes al conflicto de la zona volcánica de la Garrotxa.
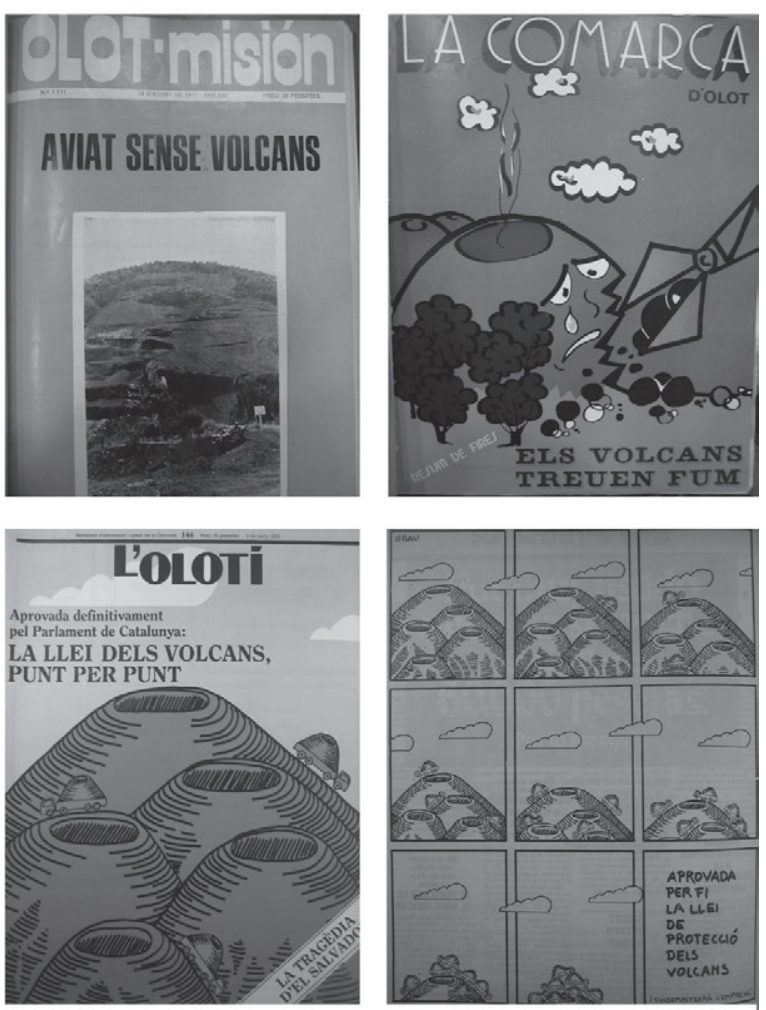

De izquierda a derecha y de arriba abajo: Olot-misión, número 1.111; La Comarca d'Olot, número 89; L'olotí, número 146 (cubierta y página 6).

mover tierras y talar árboles, actuaciones necesarias para su actividad extractiva. Finalmente, esta posibilidad no se materializó, y la alcaldía impuso una multa de medio millón de pesetas a la empresa, que además decidió añadir una donación de 3,5 millones de pesetas más. Los alcaldes de Olot y Santa Pau estaban entre los que presentaron una instancia para que desde el Gobierno central se paralizaran las extracciones y se protegieran determinadas zonas de la comarca, y el Ayuntamiento de Santa Pau encargó la redacción de las Normas Subsidiarias y del Catálogo de Protección del Paisaje de Santa Pau a miembros de la CPPZV y la CCA. La Comissió Provincial d'Urbanisme de Girona anotó determinados espacios de la zona volcánica que pertenecían al municipio de Santa Pau en el Catàleg de béns objecte de protecció, y la Diputació de Girona adquirió la parte más importante de la Fageda d'en Jordà. En cuanto al caso de los Aiguamolls, el Ayuntamiento de Castelló d’Empúries, que en su momento había dado permiso al plan de urbanización, firmó la paralización de las obras en diversas ocasiones. A nivel autonómico, fue el Parlament de Catalunya el que aprobó las distintas leyes de protección de los espacios, así como la Llei d'espais naturals de 1985. Ahora bien, esas leyes no siempre supusieron una protección efectiva de los espacios, como lo demuestran las extracciones de greda del Croscat, que no se paralizaron hasta 1991.

\section{CONCLUSIÓN}

Los años 70 y 80 fueron una época de cambio en Cataluña, no solo político, sino como se ha visto, también en cuanto a la concienciación ambiental de la sociedad, que se movilizaba con una cierta prontitud y perseverancia para reclamar lo que creía importante, fuera cual fuera el ámbito de sus reivindicaciones. Esta faceta es relevante a la hora de contextualizar y valorar la importancia de las movilizaciones populares a favor de la protección de espacios naturales, que hay que encuadrar necesariamente en una época de explosión de participación ciudadana muy activa y reivindicativa en todos los aspectos, ya fueran políticos, sociales, laborales o ambientales.

El análisis de los casos de la Zona Volcànica de la Garrotxa y los Aiguamolls de l'Empordà permite establecer claros paralelismos entre ambos. Mientras que la práctica mayoría de espacios protegidos hasta la fecha habían sido impuestos por la Administración sin consultar a la población local, e incluso a pesar de su oposición, en estas dos zonas fue la población local quien reclamó a la Administración que actuara para asegurar su protección. Ahora bien, el apoyo y la movilización popular no habrían sido posibles sin una previa concienciación, hecho del que eran sumamente conscientes tanto la CPPZV como el GDAE, cuya principal tarea fue la divulgación de los valores naturales de sus respectivas zonas entre la población local, para así conseguir su apoyo y, por tanto, poder hacer presión y ganar legitimidad ante la Administración. En el caso de la zona volcánica, la CPPZV tuvo claro desde el primer momento que era necesario dar a conocer los valores naturales de la zona porque buena parte de la población no sabía qué era lo que se estaba extrayendo, ni era consciente de que lo que se estaba destruyendo eran volcanes. Por otra parte, las características y los valores de ambas zonas eran considerablemente diferentes de los de los espacios naturales protegidos hasta la fecha, la mayoría de ellos por razones estéticas y paisajísticas. Es realmente interesante el cambio de percepción acerca de las marismas, hábitats que históricamente se habían con- 
siderado un foco de enfermedades como el paludismo y la malaria y en consecuencia se habían desecado, y que se acabaron convirtiendo en una zona protegida, si bien había un antecedente en el Parque Nacional de Doñana. En el caso de la zona volcánica es interesante señalar la dificultad del patrimonio geológico en comparación con el patrimonio biológico a la hora de ser valorado (Mallarach, 1998), y más teniendo en cuenta que la formación volcánica en la Garrotxa dista de ser tan espectacular como otras zonas protegidas anteriormente (Parques Nacionales del Teide, de la Caldera de Taburiente y de Timanfaya). Por otra parte, el principal argumento que esgrimían las empresas minera y constructora era la creación de puestos de trabajo y riqueza para la población local. En el caso de la Garrotxa, la CPPZV había expresado que la ocupación y riqueza derivados de la explotación minera sólo alcanzaban a unos pocos, mientras que la degradación de las carreteras y la contaminación provocadas por el tráfico de camiones afectaban a toda la población. Pero la carta más importante que jugaron la CPPZV y el GDAE para ofrecer una alternativa económica que les ayudara en su tarea de convencer a sus paisanos fue el turismo que atraían las zonas protegidas en todo el mundo. La CPPZV fue a visitar el Parque Natural Regional de los Volcanes de Auvernia, en Francia, y a su regreso explicó a través de la prensa el éxito turístico del Parque. En el caso de los Aiguamolls, estaba el precedente español del Parque Nacional de Doñana.

Tanto la CPPZV como el GDAE buscaron activamente el apoyo, no solo de la población local, sino también de los medios de comunicación, cuyo papel en ambos casos, si bien no todo lo imparcial que se le supone, fue crucial para la difusión de los conflictos, para que se hablara del tema y para lograr hacer presión de cara a las administraciones. En un momento de recién recuperada libertad de prensa, radio, televisión y prensa escrita eran medios de comunicación de masas realmente eficaces a la hora de alcanzar a la gran mayoría de la población. Las reivindicaciones de la CPPZV y el GDAE no habrían tenido el alcance que tuvieron si no hubieran aparecido de manera repetida en los medios de comunicación autonómicos y nacionales. Hay que tener en cuenta que ambas campañas duraron ocho años, y que, si bien con una intensidad variable, durante todo ese periodo los medios se hicieron eco de sus actividades y de cómo evolucionaban los conflictos, lo que permitió que se dieran a conocer entre la población no local. En cuanto a los medios de comunicación locales y regionales, jugaron un importante papel en la formación y concienciación de la población local, sobre todo el semanario Olot-misión /
L'Olotí en el caso de la Garrotxa, con una política claramente a favor de la campaña y que contó con uno de los miembros más activos de la CPPZV como colaborador durante un tiempo. En el caso de los Aiguamolls, la participación de periodistas en la acampada en la zona de las obras es otra muestra de la implicación de los medios de comunicación a favor de la protección de esos espacios naturales.

Es interesante tener en cuenta que en Cataluña existía desde 1955 el Parc Nacional d'Aigüestortes i Estany de Sant Maurici, protegido básicamente por sus valores estéticos y sin consultar a la población local. Una característica curiosa de este Parque es el aprovechamiento hidroeléctrico de algunos de sus lagos mayores, con los impactos ecológicos y paisajísticos que esto conlleva, y la explotación forestal que estuvo permitida hasta 1975 , dado que la mayor parte de la superficie del Parque era de propiedad privada. Alrededor de 1976 se comenzó a hablar de la ampliación de los límites del Parque, iniciativa que si bien contó con el apoyo de numerosas entidades excursionistas y ecologistas, así como de profesores universitarios, también contó con una cierta oposición local. Esta propuesta se dejó aparcada hasta que finalmente en 1988 se amplió la superficie protegida y se incluyó una zona periférica con una regulación de sus usos.

El análisis de las leyes sobre gestión y protección de la naturaleza permite darse cuenta de los cambios en cómo se la percibe. Las nuevas leyes sobre espacios y especies protegidas aprobadas a partir de la década de los 70 tienen en cuenta el valor natural intrínseco de las zonas a proteger, y no solo su utilidad para las personas. Por otra parte, las nuevas leyes son también más "democráticas", tanto al introducir el uso humano del espacio y nuevas herramientas de gestión que tienen en cuenta a la población local como al ser el resultado de una petición popular. A estas leyes hay que añadir la legislación en materia de medio ambiente referente a la planificación territorial, hasta entonces prácticamente inexistente, y a la gestión de residuos, dos ejemplos más de esta nueva percepción de la naturaleza de la sociedad.

Así pues, se puede decir que se dan ciertos elementos de continuidad entre la época franquista y la democracia en lo que a la política sobre medio ambiente se refiere. Quizá el principal de ellos sea la existencia de leyes de protección de espacios naturales y las áreas protegidas en sí. A pesar de los cambios legislativos ocurridos, hay figuras de protección y espacios naturales protegidos que se mantienen, si bien con cambios, sobre todo en su delimitación y gestión. Otro elemento 
de continuidad es el ICONA, que siguió ejerciendo sus funciones hasta que en 1991 fue sustituido por la Dirección General de Conservación de la Naturaleza.

En otros aspectos, en cambio, podemos afirmar que hay una cierta discontinuidad en cuanto a la política sobre medio ambiente entre la época franquista y la democracia, como muestra el hecho de que las competencias en esta materia fueran asumidas por la mayoría de las Comunidades Autónomas, de modo que se multiplicó la cantidad de normativas, así como una creciente influencia de normativas internacionales a partir de la década de los 90, que supuso la incorporación de nuevos requisitos a tener en cuenta por parte de la Administración y nuevas oportunidades y apoyo para los movimientos ecologistas. Las nuevas leyes estatales y autonómicas aprobadas también suponen una cierta ruptura, como ya se ha dicho, puesto que por ejemplo incluyen nuevas figuras de protección como el Parque Natural, quizá la más importante de ellas por

\section{BIBLIOGRAFÍA}

Anderson, C. B., Likens, G. E., Rozzi, R., Gutiérrez, J. R., Armesto, J. J. y Poole, A. (2008). Integrando la Ciencia y la Sociedad a través de la Investigación Socio-Ecológica de Largo Plazo. Environmental Ethics, 30, pp. 81-99. http://dx.doi.org/10.5840/enviroethics200830Supplement59

Armiero, M. (2011). A Rugged Nation. Mountains and the Making of Modern Italy. Nineteenth and Twentieth centuries. Cambridge: White Horse Press.

Armiero, M., Von Hardenberg, W. G. (2014). On History, Nature and Nation. An Interview with David Blackbourn. Environment and History, 20, 1, pp. 143-159. http://dx.doi.org/10.3197/096734 $014 \times 13851121443562$

Barca, S. (2008). Scienza, genere e storia ambientale. Riflessioni a partir da La morte della natura. Contemporanea, XI, 2, pp. 333342. [En línea]. [Fecha de consulta: 5 de agosto de 2015]. Disponible en: http://www.ces.uc.pt/myces/UserFiles/livros/648_ Scienza,\%20genere\%20e\%20storia\%20ambientale.pdf.

Bassols Isamat, E. (2010). El proceso de protección de la zona volcánica de la Garrotxa. En: VV.AA. Máster en Espacios Naturales Protegidos: La gestión activa en marcha. 16-19 de junio de 2010. Parque Natural de la zona volcánica de la Garrotxa. Espacio de Interés Natural del Alta Garrotxa. Dossier. [En línea]. [Fecha de consulta: 5 de agosto de 2015]. Disponible en: http:// parcsnaturals.gencat.cat/web/.content/home/zona_volcanica_de_la_garrotxa/coneix-nos/centre_de_documentacio/ fons_documental/biblioteca_digital/jornades_i_exposicions/2010/2010_master_enp_10a_ed/201006_dossier_master_enpred.pdf

Blackbourn, D. (2007). The Conquest of Nature. Water, Landscape, and the Making of Modern Germany. New York - London: W. W. Norton \& Company. su nivel de protección y su amplia aplicación en todo el territorio, que introducen el uso humano del espacio y la población local como elemento imprescindible en la gestión de estas zonas; tienen en cuenta valores de las nuevas zonas a proteger que van más allá de los paisajísticos o estéticos; afectan a las delimitaciones, la gestión y las reglamentaciones de las zonas ya protegidas; y conciben al ser humano como parte de su entorno, en el que ha actuado durante milenios, y del que no se puede disociar. Otro cambio muy importante es la protección de determinados espacios en respuesta a peticiones populares, mientras que hasta 1975 las poblaciones cercanas a las áreas protegidas no habían sido tenidas en cuenta. No hay que olvidar la nueva legislación referente a la planificación territorial, a la gestión de residuos y de recursos naturales, a la contaminación atmosférica y a un largo etcétera, y que cubrió el vacío existente hasta la fecha en numerosos temas relacionados con el medio ambiente.

Boada, M. y Saurí, D. (2002). El canvi global. Barcelona: Rubes.

Bolòs, O. de (1973). La conservación de la Naturaleza y sus fundamentos. Discurso leído en la sala de actos de la delegación en Barcelona del Consejo Superior de Investigaciones Científicas el día 26 de abril, en la sesión solemne dedicada a San Isidoro. Barcelona: Consejo Superior de Investigaciones Científicas. Delegación de Barcelona.

Bowler, P. J. (1998). Historia Fontana de las ciencias ambientales. México: Fondo de Cultura Económica.

Brimblecombe, P. (1987). The Big smoke: a history of air pollution in London since medieval times. London: Routledge.

Camarasa, J. M. (2007). El Llibre blanc de natura: el reconeixement de la natura com a forma d'ordenació del territorio. En: Pie, R. (ed.) Aportacions catalanes en el camp de la urbanística i de la ordenació del territorio, desde Cerdà als nostres dies. Barcelona: Societat Catalana d'Ordenació del Territori, pp. 305-337.

Carson, R. (2001). Primavera silenciosa. Barcelona: Crítica.

Casado, S. (2009). Un siglo de parques nacionales. Historia y futuro de los parques en España. Madrid: Fundación Fernando González Bernáldez. EUROPARC-España.

Casado, S. (2010a). Naturaleza patria. Ciencia y sentimiento de la naturaleza en la España del regeneracionismo. Madrid: Marcial Pons.

Casado, S. (2010b). Historia de la ciencia ecológica en España. Cuadernos de Sostenibilidad y Patrimonio Natural, 18, pp. 9-53.

Corral Broto, P. (2011). Sobreviviendo al desarrollismo. Las desigualdades ambientales y la protesta social durante el franquismo (Aragón, 1950-1979). Ager. Revista de Estudios sobre Despoblación y Desarrollo Rural, 10, pp. 111-155. 
Corraliza Rodríguez, J. A., García Navarro, J. y Gutiérrez del Olmo, E. V. (2002). Los Parques naturales en España: conservación y disfrute. Madrid: Fundación Alfonso Martínez Escudero.

Cronon, W. (ed.) (1996). Uncommon Ground. Rethinking the Human Place in Nature. New York - London: W. W. Norton \& Company.

Díez de la Paz, A. (1993). Ecología y pesca en Canarias: una aproximación histórica a la relación hombre-recurso. Ayer, 11, pp 207-231.

Folch, R. (1976). Natura, ús o abús? Llibre Blanc de la gestió de la natura als Països Catalans. Barcelona: Barcino.

Hughes, J. D. (2007). Environmental Impacts of the Roman Economy and Social Structure: Augustus to Diocletian. En: Hornborg, A., McNeill, J. R. y Martínez-Alier, J. (eds.). Rethinking Environmental History. World-System History and Global Environmental Change. New York: Altamira Press, pp. 27-40.

Mallarach, J. M. (1998). El vulcanisme prehistòric de Catalunya. Girona: Diputació de Girona.

Martínez Alier, J. (2006). El ecologismo de los pobres. Conflictos ambientales y lenguajes de valoración. Barcelona: Icaria Antrazyt.

McNeill, J. R. (2003). Algo nuevo bajo el sol. Historia medioambiental del mundo en el siglo XX. Madrid: Alianza Ensayo.

Merchant, C. (1989). The Death of Nature: Women, Ecology and the Scientific Revolution. San Francisco: Harper \& Row.

Merchant, C. (2004). Reinventing Eden: The Fate of Nature in Western Culture. New York: Routledge.

Merchant, C. (2007). American Environmental History: An Introduction. New York: Columbia University Press.

Mulero Mendigorri, A. (2002). La protección de espacios naturales en España: antecedentes, contrastes territoriales, conflictos y perspectivas. Barcelona: Mundi-Prensa.
Worster, D. (1988). Doing Environmental History. En: Worster, D. (ed.). The Ends of the Earth. Perspectives on Modern Environmental History. Cambridge: Cambridge University Press, pp. 289-307.

Worster, D. (1993). The Wealth of Nature. Environmental History and the Ecological Imagination. New York: Oxford University Press.

\section{Recursos de Internet}

Camprubí, L. (2014). La invención de la naturaleza: de la Guerra Fría al cambio climático. Ciència 3D, Universidad Autónoma de Barcelona. [En línea]. Disponible en: https://www.google. es/?gfe_rd=cr\&ei=2BObWMtlwazzB-zsupAD\#q=La+invenci\%C3\%B3n+de+la+naturaleza:+de+la+Guerra+Fr\%C3\%ADa+al+cambio+clim\%C3\%A1tico

Folguera, R., Fernández de Castro, D. y Parrado, R. (2013, 3 de diciembre). Entre el cel i la terra. 30 anys d'aiguamolls de l'Empordà. Documental emitido por TV3.

Potocnik, J. (2010). Money can't be eaten. En: Natural capital. The economics of ecosystems and biodiversity. Our Planet, the magazine of the United Nations Environment Progreamme (UNEP), september 2010, pp. 24-25. [En línea]. [Fecha de consulta: 5 de agosto de 2015]. Disponible en: http://www.unep.org/pdf/ OP_sept/2010/EN/OP-2010-09-EN-FULLVERSION.pdf

Turchetti, S. et al. (2012). The Earth Under Surveillance. Viewpoint. Magazine of the British Society for the History of Science, 98, pp. 1-3. [En línea]. [Fecha de consulta: 5 de agosto de 2015]. Disponible en: http://www.bshs.org.uk/wp-content/uploads/ eViewpoint-98-web.pdf 